\section{Trivial pursuits in the new MRCPsych examination?}

\section{DeAr SIRS}

As a recent graduand of the old-style MRCPsych, I would like to express a reservation about one particular aspect of the new-style MRCPsych examination ${ }^{1}$ to be introduced this year: the increase in emphasis placed upon the Multiple Choice Question. In the two old parts of the test a total of 600 multiple choice questions have been set (120 stems with five subquestions within each stem), in two papers. In the new examination a total of 750 questions will be asked in three papers and it is not clear from the Working Party's paper what implications this will have in the overall marking.

In the Working Party document, the debate for and against multiple choice questions is summarised. Criticisms include the fact that only certain areas of psychiatric knowledge are adequately tested in this way, that vast areas of psychiatric knowledge do not lend themselves to dichotomous testing of the true/false type and that the exam format itself encourages rote learning and the cueing of answers to particular questions. The principal advantages are its reliability and high validity.

I would like to emphasise two particular points concerning the concept of 'validity' as applied to the multiple choice examination. Firstly, since the introduction of multiple choice questions into medical examinations, it has become increasingly apparent that there are particular grammatical cues and techniques, knowledge of which confers an advantage to the well prepared candidate. ${ }^{2.3}$ This is obviously of considerable importance to both examiner and examined and creates an area of study for the candidate that is irrelevant to the task of training in psychiatry, but is essential to the task of becoming a psychiatrist.

Secondly, there is the issue of rote learning and cueing answers from previously seen questions. All psychiatric trainees, and no doubt most psychiatric tutors and examiners, will be aware of the many libraries of multiple choice questions which have been culled from various sources, textbooks, the Royal College, recollections of examination questions etc., that circulate among trainees preparing for the MRCPsych examinations. The vast majority of studying and learning time which is devoted to preparation for the examinations will be spent by many candidates in rote learning from these data bases. Unfortunately, these data bases are not directly relevant to psychiatry in practice, but simply to that restricted part of the syllabus that lends itself to testing in this fashion.

The analogy to the newly-popular general knowlege game is not as facetious as it sounds. Those of us who have played this party game on more than one occasion rapidly come to recognise previously experienced questions. It would not be difficult to train to excel at this particular pastime. A brief review of the psychiatric textbooks available in any leading bookshop will demonstrate the huge industry that the trivial pursuit of multiple choice question paper is generating (books primarily about multiple choice examinations and only secondarily about psychiatry). This supports my hypothesis that the validity of the MCQ paper is an internal validity, not one that is generalisable.

An alternative format is after all available. The shortanswer paper encourages a wider framework for learning. It tests both conceptual and factual knowledge. Its introduction is to be commended and I await with interest the next review of the MRCPsych examination in 10 years' time.

ROGER WILLIAMS

Paxton House,

57 Bath Road, Reading RG3 2BA

ReFERENCES

${ }^{1}$ Royal College of Psychiatrists (1985) Working Party for the Review of the MRCPsych.

${ }^{2}$ ANDERson, J. (1976) The Multiple Choice Question in Medicine. Tunbridge Wells: Pitman Medical.

${ }^{3}$ SLADE, P. D. \& DEWI, M. E. (1983) Role of grammatical clues in Multiple Choice Questions: an empirical study. Medical Teacher, 5, 146-148.

\section{Preliminary Test}

\section{DeAr SirS}

I write in response to Dr Sevitt's request for views on the MRCPsych Preliminary Test (Bulletin, September 1986, 10, 248-249). The idea of a fixed pass mark is, at first sight, an attractive one, but which must prove to be impractical. No two papers will be equivalents and therefore a 'pass-grade' is evolved retrospectively, based on the results achieved. An examination is inevitably discriminatory in several ways, but in the light of February statistics (a $46 \%$ pass-rate), the assertion that the 'hurdle' is becoming too great seems to be an exaggerated statement. The pass-rate for the MRCP, for instance, is much lower.

The most important issue which Dr Sevitt raises is whether the examination itself is satisfactory. Trainees are required to compete against each other; perhaps the desired outcome is 'to weed out those who aren't up to further training.' Such competition can have a less happy outcome, leading to very suitable and committed trainees being lost to psychiatry, and here I concur with Dr Sevitt's comments concerning distractions from clinical training.

The weeding-out procedure may also be seen to service the function of preventing further bottlenecks within the career structure of psychiatry. If this is true, then the blame for the disappointments of Dr Sevitt's trainees might rightfully be directed towards the Planning Advisory Committees dictating the numbers of medical graduates entering the discipline. I would respectively suggest that it is towards manpower decisions that the College directs its energies when acting for its potential future members. Examinations will always bring disappointments and dissatisfactions for some, but these may be usefully lessened if the ambiguities underlying them can be separated out and approached as individual issues.

RICHARD EYRE

The Maudsley Hospital

London SES 